\title{
LA MEMORIA COMO OBJETO DE ANÁLISIS EN LA HISTORIOGRAFÍA URUGUAYA
}

\author{
Juan Andrés Bresciano \\ Profesor agregado (grado 4). Universidad de la República, \\ Facultad de Humanidades y Ciencias de la Educación, \\ Instituto de Ciencias Históricas, Departamento de Historiología
}

\begin{abstract}
Resumen
El presente artículo analiza el modo en que la historiografía uruguaya considera, desde una perspectiva teórico-metodológica, los fenómenos relacionados con la memoria. Para ello, se centra en algunos temas fundamentales: la diferenciación entre memoria y conocimiento histórico, el uso crítico del recuerdo como fuente para el estudio del pasado, y las relaciones entre discurso historiográfico, memoria e identidades.
\end{abstract}

Palabras clave

Memória $\bullet$ historiografia $\bullet$ Uruguay.

\section{Correspondência}

Departamento de Historiología - Universidad de la República

Magallanes 1577 - CP 11200

Montevideo - República Oriental del Uruguay

E-mail: jabresciano@fhuce.edu.uy 


\title{
MEMORY AS OBJECT OF ANALYSIS IN THE URUGUAYAN HISTORIOGRAPHY
}

\author{
Juan Andrés Bresciano \\ Associate Professor (Level 4). Universidad de la República, Facultad de Humani- \\ dades y Ciencias de la Educación, Instituto de Ciencias Históricas, Departamento de Historiología
}

\begin{abstract}
The present article discusses the way in which the Uruguayan historiography considers, from a theoretical and methodological perspective, some phenomena related to memory. For that purpose, this article focuses on some basic aspects: the distinction between memory and historical knowledge, the critical use of personal memory as source for the study of the past, and the relationship among historiographical speech, memory and identities.
\end{abstract}

\section{Keywords}

Memory $\bullet$ historiography $\bullet$ Uruguay.

\section{Contact}

Departamento de Historiología - Universidad de la República

Magallanes, 1577 - CP 11200

Montevideo - República Oriental del Uruguay

E-mail: jabresciano@fhuce.edu.uy 


\section{Introducción}

En el transcurso de las últimas tres décadas, la memorialística resurge como género en el ámbito de la producción bibliográfica uruguaya. Desde los años ochenta, se publican memorias relacionadas con figuras relevantes del quehacer nacional, así como textos referidos a una localidad o una ciudad determinada, o a prácticas sociales y culturales, que se asocian con determinadas instituciones, entidades o grupos. Este fenómeno no deja indiferente a la historiografía local, ya que también en décadas recientes produce obras en cuyo título figura claramente el término "memoria". Lo mismo acontece con la producción científico-social, ya sea sociológica, antropológica o politológica. El acentuado interés por la temática desborda el mundo académico y se proyecta al ámbito político y al de la sociedad civil. Se instituye, así, el Día del Patrimonio (tangible e intangible) y se abren museos que buscan recuperar y preservar distintas clases de memorias.

Esta tendencia que se constata en el ámbito local, lejos de responder a una dinámica autónoma, obedece a procesos regionales y mundiales, que la explican en sus aspectos sustanciales. Dentro de ellos, podrían referirse dos de los más significativos:

(i) La conformación de los estudios de la memoria como campo interdisciplinario. Se trata de un nuevo ámbito en el que participan la Ciencias Históricas, la Sociología, la Filosofía, la Psicología, y las Neurociencias, entre otras disciplinas. El aporte estrictamente historiográfico a estos estudios, se expresa a través de obras magistrales como Le lieux de memoires, ${ }^{1}$ publicación colectiva en seis volúmenes dirigida por Pierre Nora, y modelo en que se inspiran diversos proyectos interesados en el abordaje del fenómeno de la memoria histórica.

(ii) Los esfuerzos colectivos por recuperar (y revindicar) las memorias de las víctimas de las diversas formas de violencia política, ideológica y militar del siglo XX: el holocausto judío, el genocidio armenio, etc. En el caso específico del Cono Sur, el interés se centra en las víctimas de la violencia política de los años sesenta y setenta y del terror de Estado.

La confluencia de los procesos referidos, genera, en el ámbito de la Historiografía de los países sudamericanos, una preocupación notoria por el pasado reciente (vinculado con las dictaduras y las transiciones democráticas), y fomenta

\footnotetext{
1 NORA, Pierre [dir.]. Les lieux de mémoire. Paris: Gallimard, 1984-1992, 7 vols.
} 
el registro y el estudio de los testimonios de los presos políticos, de los exiliados y de todos aquellos que fueron, directa o indirectamente, afectados por los regímenes autoritarios del período. En lo que respecta a la producción historiográfica uruguaya, tales temas (aunque no son los únicos vinculados con la memoria) motivan no sólo trabajos empíricos sino ensayos teóricos. Estos últimos, al tiempo que se basan en los aportes de autores europeos, norteamericanos y latinoamericanos, profundizan en diversos aspectos de la memoria colectiva y de la memoria histórica, a partir de análisis de procesos y eventos de carácter local.

El presente artículo se propone analizar algunas de estas reflexiones teóricas que se plantean en los trabajos historiográficos, organizándolas a partir de ocho tópicos fundamentales: (i) la relación entre memoria y conocimiento histórico; (ii) la memoria como insumo historiográfico; (iii) la memoria como componente del discurso historiográfico; (iv) la memoria y su relación con los repositorios documentales; (v) la memoria colectiva y sus características generales; (vi) la memoria histórica y su vínculo con las memorias y las identidades colectivas; (vii) las formas de la memoria colectiva; (viii) los conflictos que oponen a las diversas clases de memorias. Cada uno de estos temas se abordará en secciones específicas, a partir de un comentario detallado de citas fundamentales que condensan lo sustancial del aporte reflexivo de los historiadores uruguayos sobre este particular.

\section{Memoria y conocimiento histórico}

Heródoto de Halicarnaso, a quien tradicionalmente se lo conoce como el padre de la Historiografía, admite tres formas válidas de alcanzar el conocimiento con respecto a eventos del pasado: (i) los recuerdos personales del investigador, si fue testigo o partícipe de los hechos; (ii) los recuerdos de testigos directos de un acontecimiento reciente; (iii) los recuerdos de testigos directos que son comunicados a sus descendientes, y que llegan al historiador como un relato transmitido de una generación a otra. En síntesis, según Heródoto, el historiador sólo debe basarse en lo que ha visto (es decir, en sus recuerdos) y en lo que ha escuchado decir a testigos directos o a sus descendientes. En este último caso, la información resulta mucho menos confiable, y debe ser contrastada con otra clase de fuentes para considerarse válida. Tucídides - el otro autor cardinal de la historiografía griega clásica -, se muestra más estricto, y sólo confía en lo que él ha observado (auto-opsia) y lo que le comunican testigos directos. ${ }^{2}$ Estos criterios (que habrían de ser los de la historiografía griega, la latina y la medieval),

$\overline{2}$ Ver MOMIGLIANO, Arnaldo. La historiografia griega. Barcelona: Crítica, s. f., capítulo 1. 
se modifican en el Renacimiento, ya que las herramientas de la crítica filológica permiten incorporar los textos como fuentes del saber histórico. Como resultado de ello, el investigador se aboca al estudio de un pasado del que no es partícipe, y su labor heurística se concentra en el análisis comparativo de documentos, y no de observaciones personales ni de testimonios orales.

Una nueva transformación se produce cuando historiografía se constituye en saber académico universitario (a comienzos de la época contemporánea), y adopta las pautas del método científico para organizar sus indagatorias. A partir de entonces, las fuentes escritas que proceden de un pasado no vivido, adquieren un valor heurístico primario, mientras que los recuerdos personales y los relatos transmitidos por testigos contemporáneos, apenas merecen alguna consideración. El "pasado vivido", por su parte, queda excluido del campo historiográfico para evitar la parcialidad del historiador-testigo, fruto de sus compromisos políticos e ideológicos.

Esos criterios han sido superados por la reflexión historiográfica del siglo $\mathrm{XX}$, ya que considera que:

(i) Tales compromisos e intereses se hallan presentes - directa o indirectamente - en el estudio de cualquier período histórico.

(ii) Las convicciones ideológicas pueden incidir en los temas que se eligen y en las hipótesis que se plantean, pero estas últimas sólo se validan con las pruebas que la investigación aporta.

(iii) Las pruebas deben someterse a un complejo proceso de crítica heurística y hermenéutica, que responde a procedimientos consensuales en el seno del mundo académico.

En este nuevo contexto, el pasado vivido forma parte del campo historiográfico, y la memoria personal adquiere un nuevo valor como fuente del saber histórico. Sin embargo, tiene notorios límites, y para constituirse en un insumo confiable, es preciso que se someta a diversas clases de análisis. En relación al vínculo entre memoria y conocimiento histórico, el historiador uruguayo José Pedro Rilla evoca una experiencia particularmente ilustrativa:

Puedo recordar todavía con bastante precisión a mi padre en sobremesa hablándonos de la dictadura de Terra. [...] Ahora creo que mi escucha de aquellos días ... era atenta, algo ingenua, vaga pero intensamente política. Gabriel Terra, presidente primero y dictador después, había venido a hacer escombros un edificio lujoso, lleno de corredores y oportunidades... [e] irrumpido para disolver los lazos que habían organizado a esta comunidad [...] Sólo mucho después, por motivos que habría que llamar 'profesionales', supe que Terra no era 
'eso', que el Uruguay Clásico - batllista - del que el terrismo era también continuación, estaba colmado de ocultas fisuras e inconsistencias. Así pues, además de la memoria armada en aquellos relatos de sobremesa, la historia como disciplina del saber social se sumaba (para ratificar, corregir, destruir a la memoria) como ruta hacia el pasado. ${ }^{3}$

Luego de esta constatación, Rilla examina el modo en que interactúan la memoria y el saber histórico, a partir de la incidencia de una de sus obras. A mediados de los años ochenta, publica - junto con Gerardo Caetano - una Breve historia de la dictadura 4 (uruguaya), primer intento por analizar la dinámica del régimen cívico-militar que gobierna al país entre 1973 y 1985. Al igual que cualquier producto historiográfico, este libro - así se afirma - se basa en una labor de conceptualización de la propia dictadura, de periodización de sus fases de desarrollo, y de selección de los acontecimientos principales. Todo ello requiere operaciones explícitas de delimitación, inclusión y exclusión de eventos, que construyen un discurso a la vez descriptivo y explicativo. La obra resultante - sostiene Rilla - adquiere una gravitación peculiar, en la medida en que los lectores asocian sus recuerdos particulares con las diversas instancias históricas que se mencionan en el texto. En consecuencia, las evocaciones personales de cada lector se reorganizan (y contrastan) a partir del orden conceptual y de la secuencia específica de los contenidos que dan forma a la Breve historia. En ciertas ocasiones, coinciden las rememoraciones individuales con las referencias fácticas e interpretativas del texto, y las primeras se sistematizan e integran a una "memoria colectiva", a partir de las indicaciones que ofrecen las segundas. Sin embargo, en otros casos, pueden darse notorias divergencias entre las evocaciones individuales y los contenidos historiográficos, particularmente en el plano hermenéutico). Lo mismo acontece con el significado que se le otorga a los acontecimientos, a los agentes y a los contextos. En cualquier caso, la Breve historia - o cualquier otro libro de corte historiográfico - suele motiva un diálogo peculiar entre la memoria individual y el saber disciplinario, ya que:

El lector integra su peripecia personal a la colectiva, reconstruye y a veces "inventa" sincronías, cruzamientos nuevos (en tanto que no pensados antes de la lectura), reinterpretaciones o correcciones de los hechos a partir de otras combinaciones. Y puede asimismo leer como ciudadano, es decir no sólo tender los hechos y procesos en la arena

3 RILLA, José P. Historia, memoria y ciudadanía. In: GIOSCIA, Laura (comp.). Ciudadanía en tránsito. Perfiles para el debate. Montevideo: Ediciones de la Banda Oriental, Instituto de Ciencia Política, 2001, p. 69-70.

4 CAETANO, Gerardo; RILLA, José P. Breve historia de la dictadura. Montevideo: Ediciones de la Banda Oriental, 1987. 
de la acción pública donde se hacen visibles los emprendimientos cívicos, sino también, sobre todo, inscribir sus propios empeños (individuales, grupales, partidarios, corporativos) recuperados ahora a partir de la dialéctica historia-memoria, en líneas más largas de reconocimiento y responsabilidad políticos. ${ }^{5}$

En su caracterización de la memoria como fuente histórica, Rilla subraya otro rasgo que la distingue del conocimiento académico sobre el pasado. Se trata de su vínculo directo y explícito con los intereses específicos ya sea del individuo o de los colectivos a los que pertenece. En contraste, el saber histórico (o, más concretamente la historiografía), se despliega como un "dispositivo crítico" que evalúa - a partir de procedimientos de análisis consensuados -, los contenidos que aporta la memoria, para reafirmarlos, negarlos o relativizarlos. Al hacerlo, utiliza el recuerdo como fuente de información y de inspiración, ya que las urgencias y las demandas de la memoria personal, permiten implementar las "agendas de investigación" de una historiografía que, acuciada por los interrogantes y problemas del presente, recurre al pasado en busca de respuestas. La selectividad y el afán pragmático (consustanciales a la memoria de todo sujeto histórico), también se encuentran presentes en la construcción del saber sobre los grandes procesos del pasado. ${ }^{7}$ Señala Rilla que tanto la memoria como el conocimiento histórico organizan y configuran las vivencias humanas individuales y colectivas, otorgándoles un significado que deriva de cosmovisiones o posicionamientos ideológicos (en lo que respecta a la memoria) o de modelos teóricos de corte académico (en lo que refiere al saber historiográfico). Sin embargo, los modos en que se construyen, validan y divulgan memoria e historia, difieren notoriamente. De la mera suma de memorias particulares, no surge la conceptualización de los procesos colectivos que desatan las vivencias concretas en los sujetos históricos:

El psicoanalista que en posesión de testimonios del horror represivo quiere extender olímpica y mecánicamente lo que conoce de un individuo a la sociedad toda, olvida que su saber es fragmentario, no generalizable, inmaduro para dominar a las demás miradas y dar cuenta de todo. Es más razonable, empíricamente más obvia, la reconstrucción del camino que lleva desde el Estado terrorista al individuo violado; las huellas de lo uno sobre lo otro son rastreables. En cambio, mucho menos asible es el trayecto inverso: no

5 RILLA, José P. Historia, memoria y ciudadanía. In: GIOSCIA, Laura (comp.). Ciudadanía en tránsito. Perfiles para el debate, op. cit., p. 72-73.

6 Ibídem, p. 72.

7 Ibídem, p. 73. 
es posible explicar la construcción o reconstrucción de un orden político y por lo tanto público, a partir de una sumatoria de subjetividades. ${ }^{8}$

En el estudio del pasado reciente, la memoria disfruta de una gravitación peculiar, puesto que los acontecimientos analizados constituyen una porción significativa de los recuerdos personales de los actores de la sociedad civil y de la sociedad política. Las dificultades en el acceso a la documentación de archivo (fruto de un plazo de embargo que en algunos países pueden limitarse a unos pocos años, mientras que en otros se extiende a varias décadas), motiva al historiador a incorporar el testimonio oral o escrito de los partícipes, como una fuente imprescindible. Sin embargo, esta inclusión no supone una subordinación del discurso historiográfico al relato testimonial. Ana Frega, en un artículo que publica en el libro Historia reciente, historia en discusión, puntualiza lo siguiente:

La investigación y la enseñanza sobre el pasado reciente en Uruguay, junto a la recopilación y ordenamiento de la información disponible, deben exponer los acontecimientos en una secuencia significativa que incorpore elementos explicativos basados en el análisis de hechos de diversa naturaleza y ritmo que escapan a la memoria individual y que forman parte de los procesos históricos de más larga duración. Como subraya Marc Bloch, los límites entre lo "actual" y lo "inactual" no se hallan en el número de años transcurridos sino en la naturaleza de los fenómenos estudiados."

El conocimiento histórico trasciende el horizonte (y los propósitos) de las memorias particulares de los testigos, ya que opera a partir de marcos conceptuales mucho más abstractos, al tiempo que valida sus enunciados factográficos y explicativos mediante la comparación rigurosa de múltiples fuentes, y el análisis de autenticidad, veracidad y representatividad de sus contenidos. Por ello, tanto el investigador que analiza el pasado reciente como el docente que en la clase expone sobre temas de historia actual, deben demostrar un rigor metodológico y didáctico, que permita deslindar instancias que parecen confundirse y mezclarse. ${ }^{10}$ Sobre este particular, Frega comenta:

... dado que el objeto de la "historia reciente" puede entrecruzarse con el recuerdo, la memoria, la "propia vida" de los historiadores, de los docentes, de los allegados, de los estudiantes y de ellos mismos, una cierta clase de "testimonio-recuerdo" está siempre

Ibídem, p. 73.

9 FREGA, Ana. Combates por la historia reciente. In: Historia reciente: historia en discusión. Montevideo: CEIU, Pnud, 2008, p. 20-21

${ }^{10}$ Ibídem, p. 22. 
presente en el abordaje del pasado próximo al aula. La aparente similitud con los materiales utilizados en los medios masivos de comunicación o la publicación de memorias o testimonios de diversos actores del proceso... pueden llevar a incorporar en el aula el uso de "testimonios" recogidos por los alumnos. ${ }^{11}$

A partir de estos señalamientos sobre las diferencias entre memoria y conocimiento histórico, el autor del presente artículo propone una caracterización de ambas modalidades, que se basa en la consideración de los siguientes aspectos:

(i) Diferencias con respecto a la naturaleza del objeto. En términos generales, los fenómenos rememorados se presentan como acontecimientos - o como procesos - relacionados con la trayectoria vital de un individuo, de un colectivo, de una sociedad, etc. Estos fenómenos acontecen en escalas temporales relativamente reducidas y en ámbitos geográficos claramente delimitados. Todos ellos poseen una "singularidad significativa", ya que se trata de eventos que se evocan por lo que tienen de único y por lo que tienen de trascendente. Esta forma de aproximarse al pasado, no es, necesariamente, la de la historiografía (entendida como una disciplina científico-social), la cual no sólo se interesa por acontecimientos y procesos, sino por los propios sistemas sociales y sus estructuras, por los grupos que los componen, por sus hábitos, por sus representaciones y por los productos simbólicos y materiales que generan. Sistemas, estructuras, grupos, hábitos etc., constituyen objetos que operan en amplias escalas cronotópicas. Su propia existencia supone ciertas continuidades y recurrencias históricas que abren las puertas a la conceptualización generalizadora.

(ii) Diferencias con respecto al propósito. La rememoración de un evento que afecta a un colectivo específico, obedece a distintos tipos de finalidades pragmáticas, ya que el acontecimiento puede: (a) constituir un componente sustancial del relato identitario del grupo en cuestión; (b) configurar un verdadero trauma colectivo, que requiera reparaciones en el presentes; (c) transmitir una enseñanza con respecto al pasado; (d) ofrecer un modelo para la acción política, social o cultural, que se aplique a contextos actuales o futuros. En cualquiera de estos casos (y en otros posibles), la preservación del recuerdo del suceso, no constituye el punto de partida de un proceso de análisis, sino la meta última de un trabajo conjunto de una o varias generaciones. Para la historiografía, determinar lo que aconteció constituye la

${ }^{11}$ Ibídem, p. 22-23. 
prima instancia del proceso investigativo, mientras que la comprensión de los procesos históricos - y no su rememoración - configura el objetivo primario. Ello no supone que el memorialista no pretenda explicar o dar sentido a los eventos que registra. Lo que ocurre es que sus marcos interpretativos suelen ser implícitos, y se manifiestan - en forma indirecta - en la narración de lo sucedido. En el trabajo historiográfico, tales marcos deben ser explícitos, ya que la determinación de los acontecimientos se subordina a un propósito mucho más amplio: el desarrollo de explicaciones que suponen grados diversos de generalización.

(iii) Diferencias con respecto al modo en que se conceptualizan los eventos. Los memorialistas no eligen con un fin investigativo los eventos que refieren, sino que los comunican en función de compromisos o intereses políticos, ideológicos, religiosos, económicos etc. El relato que producen no configura la culminación de un proyecto de investigación, sino la comunicación de recuerdos que organizan a partir del modo en que vivenciaron e interpretaron tales eventos. Por el contrario, el historiador parte de la necesidad de dilucidar un problema - desde su presente -, y es ese problema el que motiva: (a) la elección de un objeto de estudio; (b) el planteamiento de hipótesis; (c) el relevamiento de la información necesaria; (d) el análisis e interpretación de los datos que proceden de las fuentes, de acuerdo a los métodos propios de la disciplina; (e) la comunicación de los resultados obtenidos, que, a su vez, pueden dar origen a discusiones académicas de distinta índole.

(iv) Diferencias con respecto al plano discursivo. Los memorialistas suelen producir relatos que se fundan en sus propios recuerdos. Los historiadores, en contraste, no sólo generan relatos, sino que además producen discursos analíticos, contextuales, interpretativos etc., que refieren a evidencias externas (documentos, fotografías, grabaciones, objetos etc.) las cuales pueden ser corroboradas, en todo momento, por los lectores.

(v) Diferencias con respecto a lo modo en que se validan los enunciados discursivos. La validez del discurso memorialista se sustenta en la certeza de que los recuerdos personales se corresponden fielmente con las experiencias vividas, y que el modo en que se organizan en el relato, reproduce la secuencia efectiva de los eventos narrados y de las relaciones casuales que existen entre ellos. Las afirmaciones de los historiadores, por su parte, se validan mediante la aplicación de una serie de reglas metodológicas consensuales, que incluyen el análisis de la autenticidad de las fuentes, así como de la veracidad, representatividad, coherencia y consistencia de la información que aportan. 
(vi) Diferencias con respecto al modo de integración en un corpus cognitivo. Mientras que los textos de los memorialistas aspiran a tener alguna incidencia genérica en la memoria colectiva de su comunidad, los resultados de una investigación historiográfica son sistemáticamente evaluados, ratificados (o rectificados) y difundidos para contribuir al desarrollo del saber disciplinario, y sólo de manera indirecta y mediada inciden en aquélla.

\section{La memoria como insumo historiográfico}

Las fuentes del conocimiento histórico admiten las más diversas clasificaciones, según sea el medio que trasmite el mensaje (textual, oral, iconográfico, audiovisual etc.), los formatos utilizados (documentos, libros, periódicos, revistas, folletos, grabaciones, fotografías etc.), la naturaleza de la información (cualitativa o cuantitativa) etc. Los relatos que refieren recuerdos personales sobre un evento, atraviesan todas las categorías y clasificaciones, pero distan de ser la única modalidad relevante. Para el estudio de ciertos fenómenos históricos (procesos, ciclos y tendencias de larga duración) o de determinadas estructuras (políticas, económicas, sociales y culturales) o de actores colectivos (clases sociales, grupos étnicos, minorías religiosas etc.), los relatos testimoniales deben complementarse con documentación estadística o con fuentes archivológicas. Aún así, la rememoración de un acontecimiento (consignada por escrito o comunicada en formal oral), se convierte en uno de los insumos habituales a los que recurre el historiador, ya que se transforma en testimonio, cuando se emplea como fuente. Según el historiador Carlos Zubillaga:

... se entiende por testimonio propiamente dicho, la "atestación de una cosa" realizada por persona que la ha presenciado o ha adquirido de ella "directo y verdadero conocimiento". La formulación de un testimonio supone generalmente un proceso mediante el cual la opinión del testigo deviene primero apreciación factual y, por fin, conocimiento (véase que no decimos conocimiento verdadero) sobre el hecho aludido. ${ }^{12}$

En esta sección, se analizarán los testimonios en dos instancias diferentes: (i) cuando asumen la forma de un texto que se origina con independencia de todo proceso investigativo; (ii) cuando, en el contexto de dicho proceso, se construyen mediante el método de la entrevista.

12 ZUBILlAGA, Carlos. Historia oral: la voz de los protagonistas. Cuadernos del CLAEH. Montevideo, $\mathrm{n}^{\circ} 36,1985$, p. 74. 


\subsection{La recopilación de testimonios documentales y la crítica heurística}

Con motivo de la utilización de testimonios para el estudio y la enseñanza de la historia reciente en Uruguay, Jaime Yaffé plantea una serie de reflexiones metodológicas, que podrían aplicarse para el abordaje de cualquier período o época. Identifica, así, seis aspectos básicos a la hora de considerar a las rememoraciones personales como fuente del conocimiento histórico:

(i) La subjetividad del testigo, en la medida en que sus referencias sobre el evento histórico, nacen de una vivencia estrictamente personal. ${ }^{13}$

(ii) La parcialidad de todo relato, ya que el testigo comunica lo que observa o lo que realiza (a partir de su rol como actor histórico), y describe sólo aquellos aspectos del fenómeno que lo involucran directamente. En tal sentido, cabe señalar que los acontecimientos históricos (aún los que se desarrollan en escalas espacio-temporales estrechas), suelen afectar a varios actores y obedecen a formas de interacción de diversos grados de complejidad, que no siempre se pueden percibir desde una única perspectiva. ${ }^{14}$

(iii) La fragmentariedad de los testimonios en su conjunto. La suma de los relatos basados en la rememoración, no genera una visión unificada, sino una yuxtaposición de percepciones con coincidencias, divergencias y discrepancias parciales. ${ }^{15}$

(iv) La visibilidad del testimoniante: no todos tienen las mismas oportunidades de difundir sus relatos. ${ }^{16}$

(v) La autoridad de la que gozan algunos actores/testigos, lo que facilita que sus recuerdos se impongan o desplacen a otros, en razón del poder o de la influencia que ejercen. ${ }^{17}$

(vi) La afectividad que caracteriza a algunos relatos sobre experiencias traumáticas. Cuando se trata del testimonio de una víctima, las evocaciones suelen tener "un efecto adormecedor sobre nuestra capacidad de analizar racionalmente sus contenidos." 18

\footnotetext{
${ }^{13}$ YAFFÉ, Jaime. El uso del testimonio en la enseñanza de la Historia reciente. In: Historia reciente, historia en construcción, op. cit, p. 51.

${ }^{14}$ Ibídem, p. 51.

${ }^{15}$ Ibídem, p. 51.

${ }^{16}$ Ibídem, p. 51.

${ }^{17}$ Ibídem, p. 51.

${ }^{18}$ Ibídem, p. 52.
} 
Frente a estos desafíos, el historiador debe realizar una serie de operaciones que distinguen su actividad de la mera recopilación ingenua y asistemática de memorias. Entre ellas, Yaffé indica las siguientes:

(i) La contextualización del testimonio propiamente dicho. Se trata de saber en qué circunstancias surge, qué clase de eventos menciona, cuál es la relación entre el testigo y los eventos etc. ${ }^{19}$

(ii) La personalización. Es preciso evaluar al propio autor de la fuente, y obtener ciertos datos biográficos básicos sobre su trayectoria y sobre su incidencia efectiva en los hechos que relata. ${ }^{20}$

(iii) La complementación y la confrontación de testimonios entre sí, y con otra clase de fuentes históricas. De este modo, se evita el problema de la parcialidad y de la fragmentariedad, al identificar inconsistencias, datos erróneos, referencias imprecisas, afirmaciones falsas, así como tergiversaciones y manipulaciones de toda índole. ${ }^{21}$

(iv) La disposición crítica frente a las rememoraciones del testigo, de modo que la carga afectiva del relato no obnubile al historiador, sobre todo cuando se narran acontecimientos penosos, que pueden despertar un sentimiento de simpatía hacia el deponente. Como bien señala Yaffé: “... la víctima, por ser víctima, no dice necesariamente la verdad o toda la verdad. No hay que otorgarle un supuesto de verdad previo al análisis de lo que nos está diciendo.”22

\subsection{La producción de fuentes orales mediante entrevistas}

Con relación a esta clase de insumos, Carlos Zubillaga en un trabajo de reflexión teórico-metodológica publicado en 1985 (y pionero para la historiografía uruguaya de este entonces) formula las siguientes apreciaciones:

... se trata de fuentes para cuya obtención entre en juego un caudal considerable de subjetividad, derivado no sólo de la voluntad del informante (del dramatismo de su relato, del grado de protagonismo que le correspondió en el suceso evocado, de sus condicionamientos ideológicos), sino de la incidencia de los prejuicios del historiador a través del diseño de su encuesta, que lo lleva a ser un co-generador de datos (un partícipe activo y comprometido

\footnotetext{
${ }^{19}$ Ibídem, p. 56.

${ }^{20}$ Ibídem, p. 56.

${ }^{21}$ Ibídem, p. 56.

${ }^{22}$ Ibídem, p. 56.
} 
con la restitución de los hechos del pasado, que se logra mediante la evocación reducida y el relato oral que es su resultado. ${ }^{23}$

Sin lugar a dudas, los recuerdos que se registran en una entrevista, presentan características muy distintas a los testimonios consignados por escrito:

(i) La producción del relato textual suele responder a la iniciativa del propio testigo, que comunica su versión de los hechos en función de la relevancia que les otorga. Por el contrario, el relato oral nace a partir de la preocupación del investigador por conocer detalles que le interesan para su proyecto.

(ii) En el típico testimonio escrito, el relato fluye en función de los recuerdos, las interpretaciones y los intereses del testigo. En el relato que surge en la entrevista, el recuerdo y la narración de los hechos se desarrollan a partir de las preguntas que el investigador plantea.

(iii) La creación del testimonio escrito puede haber acontecido años, décadas, siglos o milenios antes que el historiador lo utilice. El testimonio oral, en contraste, surge a partir de un proyecto que el investigador emprende.

Desde todo punto de vista, el historiador es co-creador de la fuente oral que nace de la entrevista. En ese proceso incide toda una serie de determinaciones, que Zubillaga enumera detalladamente:

(i) La selección del entrevistado. Suelen aplicarse diversos criterios: la participación directa del deponente en los hechos, el papel que desempeñó en ellos, la representatividad de su testimonio etc. ${ }^{24}$

(ii) La elección del tipo de entrevista que se llevará a cabo (abierta o cerrada), la definición de las preguntas y el diseño del cuestionario propiamente dicho. Estas determinaciones técnico-metodológicas resultan esenciales porque condicionan los contenidos y la estructura del futuro testimonio. Si se modifica el tipo de entrevista, o se cambian la clase de preguntas, las evocaciones personales pueden verse afectadas. ${ }^{25}$

(iii) La realización y registro de la entrevista, por los medios que resultan más apropiados. Las circunstancias del diálogo entre entrevistador y entrevistado inciden en el propio testimonio. La elección del momento y del

\footnotetext{
${ }^{23}$ ZUBILLAGA, Carlos, op. cit., p. 73-74.

${ }^{24}$ Ibídem, p. 76.

${ }^{25}$ Ibídem, p. 76.
} 
lugar para la entrevista, el grado de confianza y de seguridad que despierte la presencia del historiador, el interés que éste demuestre por determinadas afirmaciones del entrevistado, constituyen una serie de factores psicológicos que condicionan las respuestas y la fluidez del intercambio. La elección del tipo de registro también gravita en la configuración del testimonio: no es lo mismo un conjunto de notas escritas que reseñan las respuestas, que una grabación sonora o que una filmación. ${ }^{26}$

(iv) La conservación de los registros en repositorios permanentes, con la documentación anexa que sea necesaria. El registro adquiere valor en la medida en que se lo utilice como insumo para investigaciones presentes o futuras, o que se lo difunda en alguna clase de edición documental. Es preciso, entonces, garantizar su preservación en un archivo de oralidad, en el que se evite el deterioro del soporte original del documento, y se incluyan todos los datos necesarios para su rápida identificación. ${ }^{27}$

(v) La clasificación de los registros y la transcripción de sus contenidos. Si las entrevistas contribuyen a nutrir los fondos del algún repositorio académico, la catalogación y el ordenamiento archivológico son imprescindibles para garantizar su utilización eficaz. La transcripción parcial o total de los testimonios, facilita las tareas de análisis, así como las búsquedas específicas de datos, sobre todo si las entrevistas se realizan no sólo para la conservación de testimonios, sino para dilucidar determinados temas, en el contexto de una investigación específica. ${ }^{28}$

Al igual que los testimonios escritos, los orales deben ser objeto de una minuciosa crítica heurística para que los recuerdos personales del entrevistado se transformen en insumos confiables de un trabajo historiográfico. Si la crítica determina que el testimonio no resulta fidedigno, no significa que carezca de utilidad. Las distorsiones voluntarias o involuntarias en la rememoración de ciertos hechos, revelan otra clase de aspectos que pueden ser igualmente interesantes. ${ }^{29}$

${ }^{26}$ Ibídem, p. 76.

${ }^{27}$ Ibídem, p. 76.

${ }^{28}$ Ibídem, p. 76.

${ }^{29}$ Ibídem, p. 78. 


\section{La memoria como componente del discurso historiográfico}

En las secciones anteriores se analizaron las relaciones que existen entre memoria y conocimiento histórico, como expresiones de la conciencia colectiva con respecto al pasado. Resta por determinar en qué medida los historiadores incorporan, en su propio discurso académico, documentos que registran los recuerdos personales de partícipes o de testigos de los eventos. Para ello, se podría diferenciar cuatro modalidades: (i) la inclusión de los testimonios como referencias informativas; (ii) la integración de los relatos como un factor de articulación del propio discurso historiográfico; (iii) la elaboración de una antología de narraciones vivenciales con relación a un tema, como producto en sí mismo; (iv) la edición crítica de fuentes.

\subsection{Los testimonios como fuentes de información}

La integración de testimonios en un trabajo historiográfico, se presenta, habitualmente, bajo la forma de citas textuales de fuentes. La transcripción de uno o varios pasajes de un documento que narra un evento, puede obedecer a varios propósitos: (i) aportar información ya validada por la crítica, a partir de una remisión directa al material del que procede; (ii) someter a análisis los contenidos de la propia fuente; (iii) contrastar los datos de la fuente con los de otras que ofrecen versiones diferentes, para determinar cuál es su grado de confiabilidad; (iv) presentar ciertos eventos desde la perspectiva de un agente o de un grupo, para estudiar sus posicionamientos ante los hechos. En cualquier caso, en el discurso historiográfico se integran fragmentos cuidadosamente seleccionados de fuentes sometidas a un riguroso proceso de crítica heurística. La remisión al testimonio original se realiza mediante las correspondientes notas bibliográficas y documentales al pie de página, de modo tal que el lector pueda corroborar la procedencia de los textos citados, y determinar si no han sido descontextualizados o manipulados, de algún modo. En términos generales, las citas conforman el material de análisis del propio discurso, y aportan los elementos probatorios que lo convalidan, ya que en todo momento, las fuentes se subordinan al texto historiográfico. Lejos de imponer su interpretación de lo sucedido, los documentos constituyen insumos para satisfacer fines cognitivos que se encuentran más allá del horizonte de los testigos. Si se los cita, es porque aportan elementos para responder a preguntas o a hipótesis que formulan historiadores años, décadas o siglos después de que son registrados. 


\subsection{Los testimonios como factor articulador del discurso}

Algunas corrientes de la historiografía contemporánea, producen textos interpretativos en los que los testimonios ya no configuran fuentes que suministran datos, sino que aportan componentes sustanciales del propio discurso. Cuando ello ocurre, el discurso no se constituye a partir de la demostración de las hipótesis del investigador o de la obtención de respuestas a sus preguntas, sino que nace de la yuxtaposición de los testimonios de agentes históricos que fueron partícipes de los hechos. Se trata de un intento de construir relatos a partir de la articulación de las visiones de los sujetos históricos involucrados. En esta clase de experiencia, muy vinculada a los talleres de oralidad y a las "historias desde abajo", el investigador no genera un discurso interpretativo propio, sino que conjuga, en un único texto, un coro polifónico de voces que cuentan una historia, desde diferentes perspectivas (no siempre compatibles). Ejemplo de ello, lo ofrece una historia de la cooperativa Manos del Uruguay realizada por un equipo de antropólogos de la Facultad de Humanidades y Ciencias de la Educación de la Universidad de la República. ${ }^{30}$ Sus integrantes entrevistaron a un número representativo del universo de mujeres artesanas que forman parte de la cooperativa, y el resultado que obtuvieron es un texto narrativo, cuyos pasajes contienen la transcripción de fragmentos de cada una de las entrevistas. Como señalan los autores de esa obra:

... la reconstrucción de la historia de Manos del Uruguay a través de sus testimonios, ofreció no pocas dificultades. En efecto, por un lado la misma riqueza contenida en los testimonios hacía difícil la elección de los más representativos o elocuentes. Por otra parte, aunque estrechamente ligado a lo anterior, teníamos versiones parciales, muchas veces complementarias entre ellas, a veces contradictorias, lo que dificultaba armar el rompecabezas. No obstante, en última instancia, lo que pretendíamos era reconstruir una historia a partir de la subjetividad de una parte de sus mismas protagonistas. Los socios adherentes y los funcionarios tendrán otras historias, enfatizarán otros puntos y otros aspectos. ${ }^{31}$

Una estructura semejante presenta el libro de Graciela Sapriza, Memorias de rebeldía, basado en las historias de vida de siete mujeres uruguayas. La obra no se organiza a partir de un texto interpretativo de la autora, sino que se articula en función de algunos testimonios de las propias figuras históricas analizadas. ${ }^{32} \mathrm{La}$

${ }^{30}$ ROSTAGNOL, Susana y otros. Las artesanas hablan. Montevideo: Ciedur; Manos del Uruguay, 1988, p. $15-16$.

${ }^{31}$ Ibídem, p. 17.

${ }^{32}$ SAPRIZA, Graciela. Memorias de rebeldia: siete historias de vidas. Montevideo: Puntosur GRECMU, 1988, p. 30. 
labor del historiador, en este caso, consiste en seleccionar fragmentos, reproducirlos y ensamblarlos para presentar un relato existencial coherente, transformando un conjunto de fuentes dispersas referidas a un sujeto específico, en un relato biográfico que nunca fue concebido como tal por dicho sujeto. En consecuencia, la compilación, lejos de constituir una mera agregación de testimonios, genera un producto nuevo, que de manera implícita hace decir a las fuentes más de lo que explícitamente dicen. A ello, se agregan los condicionamientos que generan los propios criterios de selección, de ordenamiento y de ensamblaje de los fragmentos. Por tal motivo, aunque se persiga el objetivo de "hacer hablar a los protagonistas", y de hacer llegar al lector sus voces, en realidad se crea un nuevo discurso, ya que los parámetros de inclusión, jerarquización y ordenamiento de los fragmentos, obedecen al marco teórico-metodológico del investigador que compila, y no se derivan necesariamente de los contenidos de las fuentes originales.

\subsection{La estructuración de testimonios como producto investigativo}

A la yuxtaposición de relatos para reconstruir una "historia desde abajo", suele sumarse otra variante: la selección de testimonios ordenados por criterios cronológicos y/o temáticos. Se trata de una variante que presenta algunas características peculiares:

(i) Las fuentes que se seleccionan transmiten recuerdos personales sobre un tema, sin que la agregación de estos testimonios genere ninguna clase de narrativa.

(ii) El discurso historiográfico se halla ausente, ya que la obra se desarrolla a partir de la transcripción sucesiva de fuentes variadas: entrevistas, cartas, artículos de prensa, documentos institucionales etc.

(iii) La labor del investigador se centra en la selección, la clasificación, el ordenamiento y la reproducción de los materiales, operaciones que generan una representación particular del tema tratado, por agregación de documentos, la cual podría ser muy diferente si se aplicasen otras pautas de inclusión/ exclusión de testimonios. En cualquier caso, estas pautas deben plantearse en forma explícita, para que el lector (sobre todo si es un investigador) conozca los supuestos en que se basan, y pueda evaluar el producto.

Un ejemplo de esta modalidad lo aporta la selección documental sobre el matemático José Luis Massera, realizada por un equipo interdisciplinario argentino-uruguayo. En la propia presentación del trabajo, se incluyen algunas reflexiones sobre la naturaleza misma del producto: 
Recordar es recorrer y contar es construir. Se trata aquí, de la mano y con la memoria y la palabra de ... Massera, de recorrer el pasado y el presente y de atesorar información hoy y hacia el futuro. [...] La entrevista permite crear el espacio para que el relato de los hechos fluya. La transcripción asegura su preservación. La divulgación garantiza el conocimiento y el reconocimiento. La documentación juega en la contrastación entre la narración y los objetos que testimonian los acontecimientos. ${ }^{33}$

\subsection{La edición de fuentes orales}

Esta clase de materiales presentan tres características diferenciales con respecto a otros productos heurísticos:

(i) La edición no tiene como propósito generar o inducir (directa o indirectamente) una visión específica sobre un tema. Por el contrario, su objetivo consiste en difundir materiales que pueden resultar útiles a futuros investigadores.

(ii) Los testimonios incluidos se acompañan de una ficha técnica, con datos básicos sobre el origen de cada fuente, el repositorio en que se encuentran, la clase de información que trasmiten, su grado de confiabilidad etc.

(iii) Algunas de las ediciones se centran en testimonios que es preciso registrar en un soporte perdurable para no perderlos definitivamente. En buena medida, las ediciones críticas de fuentes orales obtenidas a partir de entrevistas, responden a esta última caracterización.

Con respecto al caso uruguayo, podría citarse ejemplo paradigmático: el trabajo de un equipo interdisciplinario que generó documentos orales referidos a la comunidad hebrea local. En el prólogo de la obra, se hace explícita la finalidad y los criterios que orientan la edición:

Desde este punto de vista, el trabajo del entrevistador es un operativo de salvamento de fuentes a favor del investigador futuro que podrá profundizar en ellos, y este operativo de salvamento abarca también el material escrito conservado en poder de las mismas personas que aportan sus recuerdos. Más aún, al planificar el proyecto de documentación comunitaria oral es forzoso dar preferencia a áreas y temas sobre los que no existe material escrito, por ejemplo, aquellos acontecimientos o circunstancias sobre los que se prefirió callar en su momento y que no fueron registrados, quedando limitados a las fuentes orales. A esto hay

${ }^{33}$ DIAMANT, Ana. BERMÚDEZ, Laura (ed.). José Luis Massera: matemático, científico, docente e investigador. Montevideo, Buenos Aires: Universidad de la República, Facultad de Humanidades y Ciencias de la Educación. Universidad de Buenos Aires, Facultad de Psicología, 1999. 
que agregar otros temas, relacionados con el contexto y con otras experiencias compartidas en sus momentos por todos, que no necesitaban explicarse por escrito. ${ }^{34}$

El libro citado se organiza a partir de un conjunto de entrevistas a integrantes de la comunidad, algunos de los cuales arriban al país en la década del treinta del siglo XX. Con el registro de estos testimonios, se garantiza la preservación de recuerdos y de vivencias que pueden servir de insumos para futuras investigaciones históricas. Al mismo tiempo, la difusión de las entrevistas, contribuye a la conformación de una memoria histórica comunitaria, que hasta ese entonces sólo se había nutrido de las tradiciones orales familiares más inmediatas. ${ }^{35} \mathrm{En}$ buena medida, este emprendimiento no se agota en sí mismo, sino que busca provocar una respuesta en otros investigadores y en otros actores sociales y culturales comunitarios, para que continúen con el esfuerzo de recuperar recuerdos individuales que permitan reconstruir una trayectoria conjunta. ${ }^{36}$

La divulgación de las fuentes orales, por su parte, plantean desafíos específicos. El investigador puede transcribirlas y compilarlas, utilizando un formato tradicional, pero también puede editar las grabaciones originales en un archivo de audio (o de video). En este caso, se trata de un producto que apunta a otro tipo de destinatarios. Como bien señala Carlos Zubillaga:

El desafío de la hora reside [...] en la difusión del propio registro sonoro, a través de montajes que permitan la experiencia intransferible de escuchar la voz de los protagonistas de la historia (los famosos y los ignorados) con la misma carga persuasiva, con la misma sensación de vida, y con la misma hondura emocional que pudo haberse pronunciado en el pasado (que se evoca). De tal forma la Historia puede convertirse en un compromiso con el presente, sin dejar de ser un camino científico para la explicación del pasado. ${ }^{37}$

\section{La memoria y los repositorios}

Desde la consolidación de la historiografía como práctica científica, los archivos constituyen centros documentales ineludibles para el estudio del pasado, al tiempo que resultan para la consolidación de la memoria histórica de los Estados y de las entidades políticas, económicas, sociales y culturales que forman parte

\footnotetext{
${ }^{34}$ RAICHER, Rosa Perla Historia viva: memorias del Uruguay y de Israel. Jerusalén: Instituto de Judaísmo Contemporáneo, 1989, p. viii.

${ }^{35}$ RAICHER, Rosa Perla, op. cit., p. viii.

${ }^{36}$ Ibídem, p. viii.

${ }^{37}$ ZUBILLAGA, Carlos, op. cit., p. 78.
} 
de ellos. La propia existencia de archivos, implica un grado particular de conciencia con respecto a la tarea de generar registros, de conservarlos, preservarlos, almacenarlos, clasificarlos, ordenarlos y describirlos en inventarios y catálogos, para que puedan ser utilizados de manera eficaz por cualquier clase de usuario. Sin embargo, los registros que se producen, rara vez se conservan en su totalidad, dado que los espacios de almacenamiento suelen ser limitados y no todos los documentos revisten la misma importancia. Como resultado de ello, se desecha - de acuerdo a criterios preestablecidos - la mayor parte de los documentos, y se conservan, pasado el tiempo, solo aquellos que poseen un "valor histórico". La tarea de selección y descarte (relacionada con el "recuerdo y el olvido" en el plano institucional), condiciona la labor de los futuros investigadores que acudan a los archivos en busca de fuentes para sus indagatorias. Sin lugar a dudas, la eliminación de documentos "no relevantes" es necesaria para la conformación de un archivo histórico, lo mismo que los olvidos y los recuerdos selectivos son imprescindibles para el desarrollo de cualquier relato existencia, se refiera a un actor, a una institución, a un grupo, a un Estado etc. No siempre la destrucción de documentos responde a expurgos basados en criterios técnicos: en algunas circunstancias, fuentes valiosas desaparecen o se dispersan por la ausencia de un repositorio específico que las custodie, o por la ineficacia de los que ya existen. En tales circunstancias, algunos investigadores se proponen una tarea que excede los límites de su labor habitual: no sólo se contentan con recabar fuentes, sino que además contribuyen a la generación de archivos relacionados con la memoria colectiva de los grupos que estudian. La creación de archivos como objetivo secundario de un proyecto de investigación, se vincula con el estudio de aquellos colectivos que:

(i) No pueden conservar su propia documentación en soportes perdurables, por circunstancias excepcionales.

(ii) No pueden organizar repositorios sistemáticos y permanentes porque carecen de una identidad histórica lo suficientemente consolidada.

A la primera clase de circunstancias, responde el caso de los judíos refugiados en el Uruguay, durante los años treinta y cuarenta. Para los investigadores locales, se dificulta reconstruir las trayectorias comunitarias de estos inmigrantes antes del ingreso al país, y durante los primeros años de su incorporación a la sociedad receptora. Por lo tanto, el desarrollo de un proyecto de Archivo de Historia Oral, como el que propone Rosa Perla Raicher, resulta de gran utilidad: 
En el marco de la investigación judía tiene [...] importancia singular para la reconstrucción de capítulos de historia sobre los cuales no tenemos documentación escrita, la época del Holocausto en especial. Los judíos en los campos de concentración, en los ghettos y en los bosques, no llevaban actas y generalmente no escribieron diarios de memorias. Hasta los años sesenta, dada la falta de conocimiento de la vivencia judía interna, se basó la investigación del Holocausto en documentos alemanes. La reconstrucción de la vida judía con el acento especialmente puesto en la vida judía mediante, promovió un cambio fundamental en la historiografía del Holocausto. ${ }^{38}$

Con relación a la segunda clase de circunstancias, podría señalarse el proyecto de Rodolfo Porrini, referido a la historia del movimiento gremial uruguayo. Este autor señala que la inexistencia de archivos históricos sindicales, no sólo dificulta la tarea de investigación científico-social, sino que obstaculiza los intentos de consolidar una memoria colectiva que no se base exclusivamente en la tradición oral más inmediata, y que se limite a un gremio en particular, sino que se proyecte al conjunto del movimiento obrero. Porrini comprueba que las organizaciones de trabajadores desarrollan un grado de conciencia histórica muy diverso, razón por la cual la importancia que le otorgan a sus propios documentos resulta disímil. A ello se agrega que los materiales que produce cada sindicato tienden a conservarse de manera provisoria, como parte de archivos personales de los dirigentes, con el consiguiente riesgo de dispersión que ello supone. Todo ello afecta seriamente a las identidades colectivas involucradas, ya que sin repositorios que conserven las fuentes, la investigación histórica se resiente, y sin trabajos historiográficos que nutran la memoria histórica, las narrativas identitarias colectivas solo se alimentan de las experiencias personales e institucionales del pasado más inmediato. ${ }^{39}$ Ante esta situación, el autor plantea algunas propuestas que resultan ilustrativas de la función que pueden cumplir tanto el historiador como el archivólogo en esta clase de contextos:

(i) La creación de una "red de archivos y repositorios" sobre el mundo del trabajo, que organice las tareas de rescate de los materiales dispersos.

(ii) La preservación de los fondos y colecciones de las instituciones gremiales que desaparecen, evitando así su destrucción o diseminación en archivos personales.

\footnotetext{
${ }^{38}$ AVNI, Haim; RAICHER, Rosa Perla [ed.]. Memorias del Uruguay y de Israel. Jerusalén: División de Historia Oral, Sección de América Latina, Instituto de Judaísmo Contemporáneo-Universidad Hebrea de Jerusalem, 1989, p. i.

${ }^{39}$ Ibídem, p. 26.
} 
(iii) La concreción de un "Archivo de historia oral / audiovisual" relacionado con el mundo del trabajo, a partir del relevamiento permanente de materiales éditos e inéditos.

(iv) El desarrollo de cursos sobre archivos históricos en los propios colectivos gremiales, para que sus integrantes adquieran conciencia de la relevancia de las fuentes que producen, y para que mediante su conservación metódica, contribuyan a la construcción de una memoria colectiva propia.

(v) La realización de talleres en que participen investigadores, sindicalistas y trabajadores para discutir estos temas en forma conjunta. ${ }^{40}$

\section{La memoria colectiva}

Maurice Halbawchs en una obra clásica titulada (precisamente) La memoria colectiva, introduce este concepto en los siguientes términos:

Aún no se ha acostumbrado a hablar de la memoria de un grupo, ni siquiera metafóricamente. Tal parece que una facultad semejante no pudiera existir ni durar más si se encuentra ligada a un cuerpo o cerebro individual. Admitamos, sin embargo, que existen dos formas que se organizan los recuerdos: agrupándose alrededor de una persona definida, quien lo contempla de una manera determinada; o bien distribuidos al interior de una sociedad, sea grande o pequeña, de la que son imágenes parciales. Existirán entonces memorias individuales y, si se quiere, memorias colectivas. Dicho de otra forma, el individuo participará en dos formas de memoria. ${ }^{41}$

En cualquiera de sus manifestaciones, la memoria colectiva depende de un proceso de transmisión intergeneracional, que preserva, en forma selectiva, ciertos recuerdos - individuales, en su origen -, y los organiza, posteriormente, en un corpus oral o en alguna clase de texto. En cualquier caso, la selección requiere, según Louis-Jean Calvet, plantearse cinco preguntas: ¿qué conservar?, ¿cómo conservar?, ¿para quién conservar?, ¿cómo transmitir? y ¿por qué transmitir? Estas preguntas no siempre se formulan de manera explícita, pero mediante las prácticas de transmisión, se constata el modo en que un colectivo las resuelve, ya sea en un modo plenamente consciente, o por un proceso selectivo en el que

\footnotetext{
${ }^{40}$ Ibídem, p. 27-28.

${ }^{41}$ HALBWACHS, Maurice. La memoria colectiva. Zaragoza: Prensas Universitarias de Zaragoza, 2004, p. 34.
} 
se adoptan pautas heredadas de generaciones previas, que no se cuestionan o que no se asumen de manera reflexiva. ${ }^{42}$

\subsection{La memoria y la tradición oral}

En las comunidades históricas que dependen de la oralidad, la selección de los contenidos que se transmiten de una generación a la siguiente, resulta más simple, en la medida en que obedecen a un abanico de posibilidades bastante limitado, fruto de las rutinas de una vida colectiva con escaso grado de diferenciación social y de división del trabajo. Los contenidos responden a vivencias significativas (por las razones que fueren) de individuos que integraron la comunidad en diferentes instancias históricas. Sus vivencias se plasman en un relato de carácter oral que memorizan algunos especialistas del grupo en cuestión, y que se integran en corpus oral de complejidad reciente. Para las sociedades ágrafas, el saber sobre el pasado se constituye, necesariamente, a partir de un corpus mnémico que crece en sus contenidos, con cada generación, y que puede modificar su estructura, cada cierto número de generaciones, cuando el pasado se reinterpreta. Si bien en la definición de los contenidos, inciden las memorias individuales, en la conformación del propio corpus oral, intervienen especialistas, cuyos criterios de inclusión y de interpretación de las vivencias transmitidas, no surgen del análisis de la sumatoria de los recuerdos particulares, sino que responden a los intereses y proyectos de un grupo dominante, ya sea un cuerpo sacerdotal primitivo, o alguna jefatura tribal. Las instancias de elección de los contenidos y de conformación del corpus mnémico, no se desarrollan, necesariamente, de manera sincrónica, ni obedecen a un plan definitivo. Numerosas investigaciones comprueban que ciertos contenidos, transferidos por cadenas generacionales de especialistas dentro de la comunidad, pueden combinarse en relatos diferentes, modificados en función de las nuevas experiencias históricas que afectan al colectivo. Sin embargo, la transmisión oral de recuerdos, no resulta exclusiva de las comunidades ágrafas. Sostiene Zubillaga que:

... el testimonio oral propiamente dicho configura el sustento de la historia oral, como rama dedicada a una peculiar generación de conocimiento histórico referido al suceder contemporáneo.[...] De tal modo, la historia oral implica una suerte de democratización

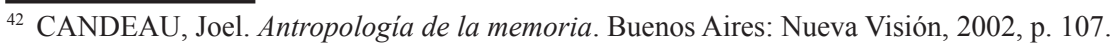


de datos, por su capacidad de apelar a todo sujeto con regular disposición mnemotécnica y determinada adscripción generacional. ${ }^{43}$

\subsection{La memoria y la escritura}

Las sociedades que se basan en la palabra escrita (sobre todo, las contemporáneas), se enfrentan a una tarea titánica, ya que:

.... las posibilidades de almacenamiento y de difusión del saber memorizado se han vuelto tan vastas en aquéllas y la cantidad de información tan abundante, que la recepción de la transmisión - finalidad de conservación - ya no está garantizada: por una parte, las capacidades de adquisición de un ser humano están limitadas; por otra, el acceso a la fuente de información (el transmisor) se ha vuelto extremadamente compleja dada la cantidad de saber que hay que procesar. Por lo tanto, hay que clasificar, elegir, olvidar y esta selección es a veces difícil y dolorosa. ${ }^{44}$

En las comunidades históricas que utilizan sistemas escriturarios, una vez que el corpus nménico se plasma en un testimonio individual o en alguna clase de discurso con respecto a eventos del pasado, éste adquiere una configuración definitiva, aunque sus contenidos puedan ser reinterpretados por otros discursos que surjan posteriormente. Mientras que el corpus oral puede experimentar modificaciones en su configuración (y depende estrechamente de los especialistas que memorizan y transmiten sus contenidos), el corpus textual - ya sea testimonial o histórico - no requiere de ninguna cadena generacional, ya que se convierte en una pieza cultural tangible y almacenable en los centros de información de la comunidad, que puede ser utilizada en cualquier momento. ${ }^{45}$ El corpus mnémico oral vive, se reproduce, se transforma y muere con las generaciones de especialistas que lo transmiten. El corpus nmémico que origina alguna clase de texto, existe y subsiste en los repositorios colectivos (bibliotecas, archivos y museos nacionales) en los repositorios particulares (bibliotecas y archivos institucionales y personales) y en las redes que socializan sus contenidos. Dentro de estas últimas, las telemáticas (y en especial, internet), contribuyen a la conformación de una verdadera memoria colectiva global. En tal sentido, se pronuncia el investigador uruguayo Hugo Achugar:

El signo inscrito en el papel de la página, pintado en la tela de los cuadros, grabado en la piedra de los monumentos o digitado sobre la pantalla líquida de las computadoras o sobre

\footnotetext{
${ }^{43}$ Ibídem, p. 75.

${ }^{44}$ CANDEAU, Joel, op. cit., p. 108.

${ }^{45}$ Ibídem.
} 
el intangible ciberespacio de las páginas web del presente mediático parece ser entendido como la memoria misma. De ahí, la historia oficial y el archivo, la biblioteca y el museo nacional - real o virtual -; de ahí, todas las otras formas de sacralización y almacenamiento de la memoria ritualizada por el poder del Estado que los seres humanos han ideado. ${ }^{46}$

\section{La memoria histórica y su relación con las identidades y las memorias colectivas}

La memoria colectiva, ya sea que se exprese como tradición oral o como un corpus de testimonios escritos que unas generaciones legan a otras, puede referir toda clase de experiencias o eventos. Ese universo de recuerdos transferidos, suele incluir desde conocimientos y destrezas fundamentales para la supervivencia de un grupo, hasta acontecimientos nimios de la vida cotidiana. Por ello, dentro de los relatos que conforman la memoria colectiva, sólo integran de manera incuestionable la memoria histórica, los que refieren acontecimientos que introducen transformaciones significativas en el desarrollo de la comunidad en su conjunto, A su vez, esa memoria depende estrechamente del desarrollo de una historiografía que contribuye a consolidarla y organizarla. Para analizar con mayor detenimiento las diferencias entre memoria colectiva y memoria histórica, conviene trascribir un pasaje del artículo que sobre este tema publica Pierre Nora, en el diccionario La nueva historia:

La memoria colectiva es lo que queda del pasado en la experiencia vivida de los grupos, o lo que estos grupos hacen del pasado. Grupos amplios, a escala de áreas culturales o naciones, de ideologías políticas o religiosas; familias más estrechas como las generaciones o los movimientos minoritarios, políticos, obreros, femeninos. [...] La memoria histórica es unitaria. Es fruto de una tradición erudita y "científica", es en sí misma la memoria colectiva del grupo de los historiadores. [...] La memoria colectiva, globalizadora y sin fronteras, vaga e interpenetrable, depende de la creencia de que no se asimila sino lo que la conforta. La memoria histórica, analítica y crítica, precisa y distinta, depende de la razón que instruye sin convencer. [...] La memoria histórica filtra, acumula, capitaliza $\mathrm{y}$ transmite; la memoria colectiva conserva un momento el recuerdo de una experiencia intransferible, borra y recompone a su capricho, en función de necesidades del momento, de las leyes de lo imaginario y del retorno de lo reprimido. ${ }^{47}$

Si se analizase una comunidad histórica reducida, con un escaso grado de diferenciación social - como las primeras culturas que emergen en el mundo antiguo -

\footnotetext{
${ }^{46}$ ACHUGAR, Hugo (comp.). Derechos de memoria. Montevideo: Facultad de Humanidades y Ciencias de la Educación, 2003, p. 39.

${ }^{47}$ NORA, Pierre. Memoria. In : LE GOFF, Jacques; CHARTIER, Roger; REVEL, Jacques (dirs.). La nueva historia. Bilbao: Retz, 1988, p. 456.
} 
el estudio de esta clase de memoria no plantea mayores dificultades. Sin embargo, a medida que tales culturas generan estructuras sociales complejas, se multiplican las formas de comunicar las vivencias de sus integrantes, se crean sistemas de información que sólo algunos de sus miembros dominan, se generan nuevas clases de discursos, y nacen formas más sofisticadas de la memoria histórica. En este caso, es preciso determinar: (i) quiénes generan la memoria histórica y cómo logran perpetuarla; (ii) qué relación existe entre memoria histórica y la producción historiográfica; (iii) cómo ambas se vinculan con las identidades colectivas.

\subsection{La conformación de la memoria histórica}

El número reducido de integrantes de las comunidades ágrafas, favorece la conformación de un único corpus mnémico oral que constituye una suerte de proto-memoria histórica del grupo. Las sociedades escriturarias, por su parte, se organizan en estructuras sociales de creciente complejidad, y transitan por procesos históricos que generan experiencias heterogéneas y multiformes. Por tal motivo, surge en ellas una memoria histórica que nace de la interacción entre dos instancias fundamentales: (i) las tradiciones orales familiares y comunitarias inmediatas; (ii) los discursos históricos de actores individuales y colectivos. Dentro de estos últimos, los que emanan del poder y de sus agentes, tienen una gravitación particular. Si el memorizador comunitario cumple un rol de relevante en los grupos ágrafos, en las sociedades complejas, los cronistas y los historiadores oficiales desempeñan un papel igualmente dinámico:

... este letrado que tiene a su cargo la transmisión de la historia "en beneficio de los actores" y "en beneficio de la posteridad" puede tener múltiples caras o posiciones. Puede ser la "bisagra", el "lazo común" entre el viejo y el nuevo orden, encargado de trasmitir el pasado sin que ello implique una ruptura que posibilite el establecimiento del nuevo y futuro orden sin generar "traumas". Puede ser, también, ya no el "articulador" sino el "intérprete" y el "filtro" de la memoria que posibilite la relectura del pasado y ofrezca las bases del nuevo relato." ${ }^{\prime 48}$

También contribuyen a la consolidación de la memoria histórica, las obras de poetas, novelistas, dramaturgos, artistas plásticos y cineastas. Carlos Demasi en un trabajo denominado La dictadura militar. Un tema pendiente, comenta lo siguiente

Es innegable la importancia que las reconstrucciones no históricas tienen en la construcción de una conciencia histórica. Así como para el caso uruguayo contribuyeron fuertemente

${ }^{48}$ ACHUGAR, Hugo, op. cit., p. 33. 
a la construcción de una historia "aceptable" (los charrúas melancólicos de Zorrilla, el ceñudo Artigas reconciliado con Montevideo en el cuadro de Blanes, las guerras civiles transformadas en páginas de heroísmo en Acevedo Díaz), es posible que las obras por el estilo cumplan la función de "representación" ante la sociedad, haciendo visibles muchas realidades que hasta ahora permanecen ocultas. Algo similar a la función que cumplieran el cine y la TV españolas en los comienzos del posfranquismo, y que en nuestro país comenzó a apuntar con obras de teatro o con el extraordinario auge de las novelas históricas. ${ }^{49}$

Cabría determinar, entonces, qué relaciones específicas existen entre memoria histórica e historiografía.

\subsection{Memoria histórica e historiografía}

En sus trabajos - centrados todos en el caso uruguayo - Demasi sostiene que la conformación de la memoria histórica nacional (de algunos períodos, en particular), es previa a la constitución del discurso historiográfico. Considera que esta memoria se construye a partir de un consenso de ciertos actores políticos y sociales con respecto al modo en que se interpreta el pasado nacional, y que luego ese consenso ofrece las claves hermenéuticas a partir de las cuales "los historiadores oficiales" elaboran sus textos. El relato interpretativo que generan se reproduce, posteriormente, en los manuales escolares y liceales, y de este modo, la memoria histórica primordial, se consolida y divulga en forma masiva. ${ }^{50}$

La memoria histórica sufre modificaciones en las diferentes fases del desarrollo de una misma sociedad, que afectan, de manera concomitante a la historiografía "oficial" del período. Por ello, a lo largo de dos siglos - como ocurre en el caso uruguayo - se suceden diversas memorias históricas, en relación biunívoca con las correspondientes historiografías oficiales. Esta clase de relación entre memoria histórica e historiografía, resulta válida para un cultivo tradicional y pre-científico de los estudios del pasado. Si bien no se puede negar que ciertos consensos sociales con respecto a la interpretación de determinados procesos, suelen incidir en los supuestos teóricos de un historiador académico, el vínculo que describe Demasi, se aplica para un modelo que concibe a la Historia como una narración explicativa de eventos, y no como un estudio de las sociedades en dimensión diacrónica. ${ }^{51}$

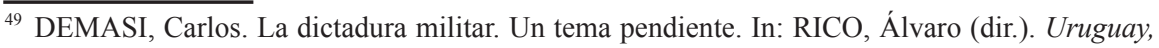
cuentas pendientes. Montevideo: Trilce, 1995, p. 44.

${ }^{50}$ DEMASI, Carlos. Educación y memoria. La escuela elabora el pasado. In: JELIN, Elizabeth; LORENZ, Federico Guillermo (comps.). Educacion y memoria. La escuela elabora el pasado. Madrid: Siglo XXI, 2004, p. 136.

${ }^{51}$ Ibídem, p. 140. 
En las últimas décadas, la memoria histórica se ha convertido en objeto de estudio de la propia historiografía. En el caso uruguayo, durante el primer lustro de la década del noventa se registran algunos aportes de relevancia. El primero de ellos, Memorias de la historia. Una aproximación al estudio de la conciencia nacional, ${ }^{52}$ de Isabella Cosse y Vania Markarian, se interesa por el modo en que ciertos discursos historiográficos inciden en la conformación de la memoria histórica de los uruguayos del presente. Para ello, las autoras realizan una encuesta de hogares, así como entrevistas selectivas, a fin de ponderar, de manera fehaciente, la influencia de tales discursos, en tópicos específicos relacionados con el pasado uruguayo. A partir de los resultados de la investigación, Cosse y Markarian comienzan a interesarse en otro aspecto también relacionado con la relación entre memoria histórica e historiografía:

Desde una preocupación por la memoria social, nos centramos en las políticas de celebración histórica del gobierno instaurado en 1973. Más precisamente, estudiamos el programa de conmemoraciones de los ciento cincuenta años de la Cruzada Libertadora, realizado durante 1975 bajo el rótulo de "Año de la Orientalidad”. [...] A lo largo de meses de investigación, recibimos tantas interpretaciones del período como personas supieron del tema. Sucede que los años de gobierno autoritario siguen gravitando en la memoria personal y colectiva. ${ }^{53}$

Esta clase de investigaciones evidencia un abordaje de la memoria histórica, en el que se relacionan los discursos oficiales y los textos historiográficos con la recepción efectiva de estos contenidos. Asimismo, pone de manifiesto que la constitución de la memoria histórica resulta un proceso particularmente complejo, ya que la recepción de los contenidos que el Estado desea transmitir a través de sus "aparatos ideológicos", nunca es unívoca, en la medida en que los ciudadanos los seleccionan, interpretan y cuestionan.

\subsection{Memorias e identidades colectivas}

En todo individuo, memoria e identidad están íntimamente vinculadas. El sujeto moderno organiza su pasado a través de narrativas autobiográficas que configuran los recuerdos y los transforman en expresión de su propia identidad. Esas narrativas pueden modificarse cuando nuevas experiencias conducen a

${ }^{52}$ COSSE, Isabela, MARKARIAN, Vania. Memorias de la historia: una aproximación al estudio de la conciencia nacional. Montevideo: Trilce, 1994.

${ }^{53}$ COSSE, Isabela. MARKARIAN, Vania. 1975: año de la orientalidad. Identidad, memoria e historia en una dictadura. Montevideo: Trilce, 1996, p. 7-8. 
una reinterpretación de las vivencias previas. ${ }^{54}$ Los mismos individuos pueden contar la historia de su vida de manera muy diferente, en distintas etapas de su vida, e inclusive, redefinir su propia identidad, al cuestionarse sobre el sentido de su propia existencia, de los problemas de su época, y de las realidades de la sociedad en que vive. Algo semejante acontece con las memorias y las identidades colectivas. Por ello, una de las identidades colectivas básicas de la época contemporánea, la identidad nacional, no puede consolidarse sino existiera una memoria histórica nacional correlativa. $Y$ en ese proceso, la enseñanza primaria y secundaria, y más específicamente los cursos de Historia, cumplen una función esencial. ${ }^{55}$ Con respecto al caso específico de la identidad nacional y de la memoria histórica uruguaya, Demasi afirma:

Esta construcción de la memoria ha servido también de fundamento a la identidad de los uruguayos, que se ven como "productos de su historia", y en las elaboraciones posteriores a la dictadura el relato muestra una sociedad muy plácida: "de cercanías" (sin posiciones extremas), "hiperintegrada" (sin profundas segmentaciones), "amortiguadora" (que evita los conflictos), "partidocéntrica" (que privilegia las instancias político-partidarias por encima de los grupos de presión social). ${ }^{56}$

La relación entre identidades y memorias no se limita sólo al ámbito del pasado nacional. De hecho, en el ciudadano corriente del tiempo actual, coexisten diversas memorias e identidades:

(i) La identidad y la memoria personal, que se sustenta en el recuerdo de las experiencias habidas.

(ii) La identidad y la memoria familiar, que se nutre: (a) de los recuerdos del individuo sobre los familiares que conoció; (b) de los recuerdos que le transmitieron sus familiares inmediatos sobre los ancestros que nunca conoció (tradición oral familiar); (c) de toda clase de documentos (textuales, iconográficos, sonoros, audiovisuales) que disponga sobre sus parientes.

(iii) Las identidades y las memorias comunitarias, que pueden referirse a un grupo local, a un grupo social, a un grupo profesional, o a un grupo étnico, a un grupo religioso etc. Todas ellas se sirven de tradiciones orales, de documentos institucionales y de relatos históricos e historiográficos.

\footnotetext{
${ }^{54}$ Ibídem, p. 117.

${ }^{55}$ DEMASI, Carlos. Educación y memoria. La escuela elabora el pasado, op. cit., p. 138.

${ }^{56}$ Ibídem.
} 
(iv) La identidad y la memoria nacional, que se alimenta de los contenidos que difunde la enseñanza primaria y secundaria, de los textos literarios, de las obras artísticas, de las producciones cinematográficas que reafirman los mitos nacionalistas (o que los cuestionan), y de todos los discursos historiográficos que refieren a ellos.

(v) Las identidades y las memorias civilizatorias, que resultan mucho más difusas que las anteriores, ya que se basan, por lo general, en tradiciones orales y discursos religiosos, filosóficos, político-ideológicos e historiográficos.

Todas estas memorias e identidades coexisten en el ciudadano contemporáneo, pero en cada individuo gravitan, se articulan, se amalgaman o se contraponen, de manera distinta.

\section{Formas de la memoria colectiva}

En la presente sección se presentan algunas variantes tipológicas de las memorias múltiples que coexisten en una sociedad. El análisis se centrará en cinco modalidades, referidas explícitamente por la historiografía uruguaya: (i) las memorias tradicionales del poder; (ii) las memorias nacionales; (iii) las memorias populares; (iv) las memorias étnicas y (v) las memorias de género.

\subsection{Las memorias tradicionales del poder}

Desde que nace la historiografía hasta que se transforma en una práctica científica, algunos historiadores cuestionan el poder a través de sus relatos, mientras que otros construyen sus marcos interpretativos a partir de la visión del pasado contenida en las memorias de los poderosos. En las sociedades premodernas, el dominio de la escritura (privilegio de unos pocos), facilita la consolidación de un discurso histórico que el poder genera para su autolegitimación, y que los cronistas oficiales consagran en sus textos. La mayor parte de los historiadores de las cortes del Antiguo Régimen, elaboran discursos que tienden a presentar como natural el orden existente, contribuyendo a la creación de una única memoria histórica, en la que los súbditos identifiquen su pasado familiar y local con el de la monarquía que los rige.

Esta función del historiador oficial, señala Achugar, parecería diluirse con el fin de los Estados dinásticos (asociados a la memoria de familias reales que ejercen el poder) y con el nacimiento de los Estados nacionales (vinculados a la memoria colectiva de una comunidad sociocultural que comparte un pasado común y un mismo proyecto político en el presente). Sin embargo, las nuevas memorias nacionales que se inculcan, mantienen, durante el siglo XIX y la mayor 
parte del XX, las características típicas de las memorias tradicionales del poder, alimentadas por una historiografía oficial que se construye "desde arriba".

\subsection{Las memorias nacionales}

A comienzos de la época contemporánea, los intelectuales y literatos que producen discursos históricos al servicio de una causa nacional, reemplazan a la monarquía por la nación como factor constituyente de la memoria colectiva, y sientan las bases de un relato que busca legitimar una identidad en proceso de consolidación. Algunos de sus textos aportan contenidos sustanciales a una nueva memoria - la estatal/nacional - que a través de la alfabetización masiva y de la escolarización obligatoria, resultará clave para la "construcción de ciudadanía" en el siglo XX. En el seno de las sociedades contemporáneas, la memoria nacional lejos se encuentra de ser la única posible, pero adquiere un protagonismo incuestionable. En sus comienzos, se apoya en los discursos históricos e historiográficos que emanan - directa o indirectamente - del Estado. De hecho, son los eventos político-nacionales los que estructuran los textos de los manuales de esta historia nacional, en la que se privilegian los acontecimientos militares y diplomáticos. Por otra parte, el Estado, mediante sus libros oficiales de enseñanza, inculca una memoria que busca prevalecer sobre las otras que posea el estudiante (la familiar, la comunitaria, la étnica etc.) ya que las subordina al macro-relato de la constitución y desarrollo de la nación. ${ }^{57}$

La descripción anterior puede aplicarse a la inmensa mayoría de las sociedades contemporáneas, hasta el último tercio del siglo XX. A partir de entonces, las memorias nacionales difundidas por la enseñanza primaria y secundaria, ya no se refieren al poder estatal y sus avatares, sino que incluyen, paulatinamente, a los diferentes actores económicos y culturales que forman parte de la sociedad. Se genera, entonces, una memoria nacional que comienza a distanciarse de la "historia desde arriba" y que incorpora diversas "historias desde abajo". Al respecto, Achugar señala que:

Una memoria democrática que intentara contar la historia de Uruguay o de la dictadura o de la restauración o del conjunto de la historia nacional, debería proceder a contar la historia como una historia múltiple y por lo mismo contradictoria. No podría contar, por ejemplo, sólo la historia de los generales o de los presidentes o de los latifundistas - para sólo referirnos al tipo de historia que da cuenta de los sujetos sociales o de los individuos involucrados en los procesos históricos - ya que debería incluir la perspectiva de los cam-

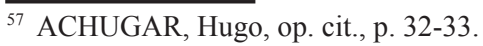


pesinos, de los sindicatos, de las mujeres, de los negros, de los iletrados, de las instituciones y asociaciones diversas, y aún así estaría olvidando a los extranjeros nacionalizados o no, a los inmigrantes y a los migrantes. Pero además estaría olvidando incluir la historia de las prostitutas, de los gays, de los discapacitados, de los locos, de los indios, de los mestizos. Y seguramente estaría olvidando a aquellos grupos, actores o sujetos sociales que yo mismo he olvidado en este momento. ${ }^{58}$

Indudablemente, una memoria nacional plural, no puede consistir en la yuxtaposición de todas las memorias concebibles, pero debe incorporar las de los actores más significativos que han incidido en el desarrollo común. Asimismo, debe reconocer (aunque no integrar necesariamente) a las memorias de los colectivos de menor visibilidad, $\mathrm{y}$, al mismo tiempo, habilitar ámbitos e instancias para su cultivo y preservación..$^{59}$

\subsection{Las memorias populares}

Como se indicó en el parágrafo anterior, la historiografía tradicional contribuye de manera significativa a fortalecer y articular las "memorias del poder". En contraste, las memorias de los grupos sociales y de las comunidades que no ejercen dominio, sino que lo padecen, nutren los relatos de cronistas e historiadores disidentes y alimentan las propias tradiciones orales, muchas de las cuales demuestran una capacidad de pervivencia sorprendente. Con la consolidación de una historia social, entendida como especialización académica en un ámbito científico, nace el interés por registrar las memorias de esas clases sociales relegadas, y de los movimientos y de las organizaciones que éstas desarrollan. Como bien señala Carlos Zubillaga, la memoria popular:

... no está cronológicamente restringida al tiempo corto de un ejercicio mnemotécnico por parte de algún participante en el quehacer de un ámbito social de base, sino que se extiende a la "memoria transferida" por las generaciones precedentes, proyectando la pesquisa histórica a un promedio de $80 / 90$ años atrás. ${ }^{60}$

El registro y análisis de tales recuerdos (transferidos generacionalmente), se constituye en una herramienta insoslayable para el estudio de la historia social, ya que sin apelar a ellos, sería imposible obtener información sobre un conjunto de

\footnotetext{
${ }^{58}$ ACHUGAR, Hugo. La nación entre el olvido y la memoria. Hacia una narración democrática de la nación. In: RICO, Álvaro (dir.). Uruguay, cuentas pendientes, op. cit., p. 22.

${ }^{59}$ Ibídem, p. 23-25.

${ }^{60}$ ZUBILLAGA, Carlos. De la memoria del poder a la memoria popular. Cuadernos del CLAEH. Montevideo, no 41, 1987, p. 27.
} 
fenómenos para los cuales las fuentes archivísticas, bibliográficas, hemerográficas y museológicas no aportan datos suficientes. Al acudir a la tradición oral, el investigador identifica fenómenos que la documentación clásica no consigna. ${ }^{61}$ Su utilización, por otra parte, plantea desafíos metodológicos específicos, ya que el historiador debe conciliar el discernimiento analítico con las vivencias intergeneracionales y grupales que les transmiten sus informantes. Finalmente, el uso de estas fuentes favorece la renovación temática entre aquellos que investigan los modos en que se organizan las clases populares.

Rodolfo Porrini se preocupa, específicamente, por las dificultades que afronta el movimiento obrero uruguayo para consolidar una memoria que trascienda los marcos de la oralidad. El primer problema se relaciona con el alto grado de dispersión de las fuentes escritas del propio movimiento, así como la precariedad de sus escasos archivos. Dado que cada gremio tiene sus repositorios y no existe una política archivística común para todas las organizaciones obreras, son altas las posibilidades de pérdida de materiales y de disolución de los fondos documentales, con los cambios de dirigencia o con las transformaciones (o desapariciones) de algunos sindicatos. ${ }^{62}$ Como resultado de ello, el investigador se ve obligado a recurrir a otras clases de memorias y de documentos: los que proceden de las grupos sociales hegemónicos y de las instituciones estatales, tanto nacionales como extranjeras. ${ }^{63}$ Estas dificultades no sólo afectan a las tareas académicas, sino que son obstáculos objetivos al desarrollo de una memoria popular que nutra una identidad - la de las clases asalariadas -, enfrentada al riesgo incesante de perder fuentes históricas valiosas para la comprensión de su pasado. ${ }^{64}$

\subsection{Las memorias étnicas}

Sociedades aluvionales como las rioplatenses, se nutren del aporte de grupos migrantes que contribuyen, en períodos diferentes, a la conformación de países signados por la confluencia de tradiciones y memorias. De esta manera, un número considerable de sus ciudadanos actuales, además de compartir una memoria nacional común (incorporada durante el proceso de escolarización obligatorio) poseen memorias familiares y comunitarias que los vinculan con otros Estados nacionales y con otras colectividades étnicas.

\footnotetext{
${ }^{61}$ Ibídem, p. 24.

${ }^{62}$ PORRINI, Rodolfo, op. cit., p. 11-12.

${ }^{63}$ Ibídem, p. 11-12.

${ }^{64}$ Algunas propuestas a esta situación se plantearon en la sección relativa a Memoria y repositorios.
} 
Se podría referir las migraciones forzadas de esclavos africanos a la Banda Oriental. Sus descendientes, organizados en la actualidad como grupo étnico en instituciones diversas (entre ellas, Mundo Afro), se interesan vivamente por recuperar sus raíces, a través de modalidades culturales que desde hace décadas gozan del reconocimiento y de la valoración de la sociedad a la que pertenecen. En consonancia con estos planteos, Walter Díaz Marrero estudia la integración de las Llamadas al carnaval tradicional uruguayo, como expresión de diálogo entre dos memorias: la étnica y la popular. ${ }^{65}$ Con respecto al modo en que se procesa esa peculiar incorporación, el autor sostiene que la realización de las Llamadas supone una re-creación de antiguos ritos:

... en un ámbito adecuado, sin riesgos ni prejuicios - un ambiente en el cual [los afrouruguayos] se sentirán tenidos en cuenta, valorados en sus recuerdos, recuperando así el valor de estar vivos para contar y ser escuchadas sus vivencias y la forma de comunicarlas. Es la manera de identificarse y ser identificados con ellas por los "otros" no afrodescendientes, pero integrantes del mismo cuerpo social. ${ }^{66}$

El estudio de la transmisión de conocimientos sobre la fabricación y la ejecución de los instrumentos vinculados con las Llamadas, no sólo permite preservar un saber específico (y las prácticas musicales y culturales que le están asociadas), sino estimular el desarrollo de una identidad tradicionalmente marginada. De este modo, el trabajo científico-social recupera y valoriza memorias de la música y de las danzas de un grupo étnico, y las relaciona e integra con las de la sociedad de la que forma parte. En cualquier caso, este último aspecto, trasciende la labor estrictamente académica, e incursiona en el campo de las políticas identitarias y culturales. ${ }^{67}$

Además de la migración forzada de población esclava, el Uruguay recibe un aporte demográfico sustancial procedente de la Europa Mediterránea, Central y Oriental, desde mediados del siglo XIX a mediados del XX. Esta circunstancia afecta a la conformación de memorias colectivas, en los siguientes aspectos:

(i) Los inmigrantes deben articular las memorias nacionales, populares y étnicas que les fueron inculcadas en sus países de origen, con la memoria nacional de la sociedad receptora. No se trata de una tarea fácil. En cualquier caso, esa

${ }^{65}$ DÍAZ MARRERO, Walter. Llamadas de tambor y etnicidad. Una máscara blanca sobre la memoria afrouruguaya. In: Antropología social y cultural en Uruguay. Anuario. Montevideo, 2006, p. 104.

${ }^{66}$ Ibídem, p. 104.

${ }^{67}$ Ibídem, p. 104-105. 
integración (o coexistencia), incide de manera notoria en la conformación de la propia identidad individual y en las narrativas autobiográficas.

(ii) La primera generación de descendientes de inmigrantes, debe articular la memoria nacional que se les transmite en las instituciones educativas, con las memorias que les comunican sus progenitores, mediante la tradición oral. Estos relatos familiares aluden a contextos geográfico-históricos que no coinciden con los de la historia nacional aprendida en las escuelas.

(iii) Algunos integrantes de las generaciones siguientes, "regresan" a la sociedad de origen de sus respectivas familias (por razones políticas o económicas), generando un nuevo diálogo entre tres clases de memorias: (a) las que le transmitieron sus ancestros con respecto al país de origen; (b) la que recibieron en las instituciones educativas del país en que nacieron; (c) la que les ofrece ese país al que "retornan", cuando deciden integrarse a él. Esta última memoria puede no coincidir con la primera, ya que sus ancestros atesoraban recuerdos de una sociedad muy distinta, que se modificó sustancialmente con el transcurso de las décadas.

(iv) El conflicto entre memorias también afecta a los inmigrantes que regresan a la sociedad de la que proceden, luego de haber vivido durante décadas en otro país. La sociedad que "reencuentran", no se corresponde con la de sus memorias infantiles o juveniles, y por ello comienzan a añorar a la sociedad que los recibió como inmigrantes. Surgen, así, cuestionamientos identitarios que se expresan de manera muy clara en una típica frase: "No soy de aquí ni soy de allá".

\subsection{Las memorias de género}

Graciela Sapriza, autora anteriormente citada, se pregunta, en varios de sus trabajos, si existe una memoria de género. No considera que las mujeres recuerden en forma distinta a los hombres, debido a alguna clase de condicionamiento biológico. Por el contrario, afirma que las mujeres, a partir de su identidad de género (entendida ésta como una construcción histórico-cultural cambiante) y en función de las realidades sociales del país y de la época en la que viven, pueden tener intereses y sensibilidades particulares, que se reflejan en una forma particular de rememorar y de significar sus vivencias. En el segundo lustro de la década del noventa, Sapriza contribuye con un proyecto que habría de dar origen a una recopilación de testimonios verdaderamente original en el contexto uruguayo: 
En 1997, a un año de iniciadas las masivas marchas por el esclarecimiento de las violaciones a los Derechos Humanos, un grupo de mujeres expresas políticas sintieron la necesidad de hablar por ellas mismas a fin de reconstruir su peripecia y aportar su visión de la historia del pasado reciente. Luego de tres años de trabajo común, decidieron convocar a un concurso de relatos sobre la dictadura exhortando a todas las mujeres a que brindaran su testimonio sobre lo que vivieron y sintieron durante esos años. ${ }^{68}$

Memorias para armar - tal es el título de la publicación - pone énfasis sobre aquellas instancias cruciales que en un contexto de violencia política y de represión, se vivencian y se recuerdan de manera diferente, en razón de la identidad de género: el amor y el compromiso político, la maternidad, la tortura, las violaciones y la humillación en un ámbito de reclusión clandestino, o en una institución carcelaria. Antes de su participación en este proyecto, Sapriza había desarrollado investigaciones tendientes a rescatar el modo en que las mujeres evocan el pasado, según los ámbitos socio-históricos en los que actúan. En buena medida, la recopilación de testimonios que presenta en su obra Memorias de rebeldia: siete historias de vida, apunta a ese objetivo. ${ }^{69}$

\section{Las memorias colectivas y sus tensiones}

Las dinámicas del recuerdo y del olvido hacen posible el flujo de la memoria, así como la permanente construcción/revisión/reconstrucción del relato identitario. Del conjunto de las vivencias habidas por el sujeto, solamente algunas se integran como recuerdos más o menos permanentes, mediante los que se cimienta la identidad. Nuevas vivencias (sobre todo las que cuestionan las certezas y las convicciones más profundas), suelen conducir a nuevas rememoraciones y a nuevos olvidos, que reescriban la narrativa existencial. Procesos análogos acontecen con las memorias colectivas, cuando los integrantes de una sociedad no pueden olvidar algunas realidades del pasado, o acatan la prohibición (impuesta o autoimpuesta) de recordar determinados hechos.

\subsection{La evocación persistente del pasado}

En ciertas comunidades, resulta frecuente la rememoración obsesiva de alguna fase particularmente exitosa de su desarrollo histórico, considerada como

\footnotetext{
${ }^{68}$ SAPRIZA, Graciela. Escritura de mujeres y memoria. In: MIRZA, Roger. Teatro rioplatense. Cuerpo, palabra, imagen: La escena contemporánea. Montevideo: Universidad de la República, Facultad de Humanidades y Ciencias de la Educación, 2007, p. 227.

${ }^{69}$ SAPRIZA, Graciela, Memorias de rebeldia: siete historias de vida, op. cit., p. 13-14.
} 
una verdadera "edad de oro". Se trata, en buena medida, de la idealización de un período previo que comparado con la situación presente, se manifiesta como una instancia de plenitud y de realización individual y colectiva. El tiempo actual, por el contrario, se desvaloriza en la medida en que los logros antes obtenidos se han perdido, o se han visto erosionados de manera sustancial. Por ello, aunque se trate de un pasado distante, se lo recuerda de manera persistente, ya sea a través de la tradición oral familiar o grupal, o mediante algunos textos históricos (e inclusive historiográficos) que alimentan la rememoración idealizadora. Un caso emblemático de esta situación se evidencia en el estudio de la antropóloga Gabriela Campodónico sobre el Frigorífico Anglo y la ciudad de Fray Bentos. ${ }^{70}$ Publicado en el año 2000, su trabajo aborda el vínculo identitario entre la ciudad uruguaya y el exitoso frigorífico que desde fines de siglo XIX hasta los años sesenta del siglo XX garantiza su prosperidad:

Si la identidad se forja como un conjunto de procesos de contrastación con lo diferente y de afirmación de las formas de lo propio, sin duda el frigorífico Anglo fue una marca muy fuerte en esta construcción identitaria. El nombre de la ciudad estuvo asociado, en el país y en el mundo, a la presencia del Anglo. [...] Los productos representaban a la ciudad, al lugar que los generaban. La identificación de la ciudad con el frigorífico era, y en parte sigue siendo, muy fuerte; la ciudad casi coincidía con la existencia del frigorífico. Desaparecido el mismo, el proceso por el cual ambos factores se disocian, aún no ha terminado, menos aún mientras se dificulta la creación de otras formas identitarias alternativas. ${ }^{71}$

Desaparecido el frigorífico, su recuerdo (inclusive entre aquellas generaciones que no lo conocieron), mitiga la sensación generalizada de incertidumbre con respecto al futuro de una ciudad que - hasta ese entonces - no encuentra ninguna actividad económica que la conduzca a un desarrollo renovado. Aún así, la referencia a un pasado que se rememora en exceso, no sólo tiene un efecto de nostalgia adormecedora, sino que reafirma la convicción de que la comunidad puede encontrar nuevos caminos que le permitan salir del marasmo. ${ }^{72}$

\subsection{Los olvidos}

A la evocación obsesiva de un pretérito idealizado, se contrapone la imposibilidad o la prohibición de recordar. Como bien señala Achugar, el olvido asume

${ }^{70}$ CAMPODÓNICO, Gabriela. [El] Frigorífico Anglo: memoria urbana y memoria social en Fray Bentos. In: Antropología social y cultural en Uruguay. Anuario. Montevideo, 2000, p. 106-107.

${ }^{71}$ Ibídem, p. 107.

72 Ibídem, p. 107. 
diversas formas, cada una de las cuales tiene un significado distinto, y se relaciona de manera diferente con la memoria colectiva. Surge, así, el "olvido inconsciente", el "olvido elegido", el "olvido impuesto", el "olvido a nivel del individuo" y el "olvido ejercido por una comunidad o por una corporación". ${ }^{73}$ Marcelo y Maren Viñar, haciendo alusión al olvido oficial impuesto con respecto a las violaciones a los derechos humanos durante el período dictatorial, profundizan sobre algunos de estos conceptos. ${ }^{74}$ Sostienen ambos autores que los actos de violencia vividos y silenciados, tienen un efecto de "marca patógena", mucho más perjudicial que las historias que relatan las víctimas, ya que aunque posiblemente distorsionadas "en los excesos de su verdad y su mentira", éstas permiten comunicar y elaborar una experiencia traumática. ${ }^{75} \mathrm{El}$ olvido, promovido primero por la dictadura, fomentado luego por los gobiernos democráticos con la aprobación y aplicación de la Ley de Caducidad de la Pretensión Punitiva del Estado, alimenta un silencio que las víctimas terminan aceptando, puesto que últimas no sólo evitan recordar los eventos traumáticos, sino que además resultan incapaces de expresarlos. Ante esta situación, Marcelo y Maren Viñar proponen: "Representar lo irrepresentable del horror [...]. El silencio (o silenciamiento) es aliado o cómplice del terror. La palabra - aún la más controversial - engendra el esclarecimiento", ${ }^{76}$

Este matrimonio de psicoanalistas constata que en el contexto político de los años noventa, los testimonios sobre la deshumanización y la violencia superlativa de la que fueron objetos los prisioneros políticos y las víctimas de la dictadura, "son rodeados de silencio e indiferencia y permanecen ajenos y sin inscripción colectiva." "77 Parecería tratarse de un "pacto social denegatorio" que confina a los sufrientes a padecer sus memorias en aislamiento, y evitar que otorguen significado al horror que experimentaron, y que integren sus recuerdos a la memoria colectiva de la sociedad en la que viven. Esta situación, fruto de una "política del olvido" promovida desde el poder y aceptada por algunos sectores de la sociedad, debilita los fundamentos de una comunidad democrática. Por ello, Gerardo Caetano, historiador y cientista político uruguayo, sostiene que:

Las fracturas de la memoria y los intentos de cerrar "a cal y canto" los caminos por la búsqueda de la verdad y de la justicia, en relación con lo ocurrido durante las dictaduras

${ }^{73}$ ACHUGAR, Hugo. La nación entre el olvido y la memoria. Hacia una narración democrática de la nación. In: RICO, Álvaro (dir.). Uruguay, cuentas pendientes, op. cit., p. 24.

${ }^{74}$ VIÑAR, Marcelo; VIÑAR, Maren. Fracturas de memoria. Crónica de una memoria por venir. Montevideo: Trilce, 1995, p. 14-15.

75 Ibídem, p. 15.

${ }^{76}$ Ibídem, p. 134.

${ }^{77}$ Ibídem, p. 125. 
de la seguridad nacional en América Latina, han afectado en sus bases a nuestros sistemas políticos y al ejercicio cotidiano de la ciudadanía. Esas "políticas del olvido", esos intentos de sustentar la impunidad en visiones y propuestas que exhortan una y otra vez a "mirar al futuro" y "dejar definitivamente atrás los malos tiempos", que invocan "la teoría de los dos demonios" o que a menudo apelan a la amenaza implícita de "no agitar las aguas del pasado" para "no despertar a los monstruos", han terminado por empobrecer la necesaria tensión de nuestro diálogo democrático y de los compromisos morales que cimientan nuestras identidades cívicas. ${ }^{78}$

Ya en el segundo lustro de los noventa, la situación comienza a revertirse con la publicación de los testimonios de presas políticas (Memorias para armar), y con algunos proyectos de rememoración colectiva, como el Memorial de los Detenidos Desaparecidos. A comienzos del siglo XXI, el proceso se acelera gracias a las actuaciones de la Comisión para la Paz, la creación del Museo de la Memoria, y la concreción de una obra colectiva - solicitada por la Presidencia de la República - en la que un equipo de investigadores lleva a cabo una labor rigurosa de exhumación de fuentes, para documentar las violaciones de los derechos humanos bajo el terror de Estado. Si bien el olvido impuesto no resulta compatible con las sociedades democráticas y plurales, no puede negarse que los olvidos forman parte necesaria de los procesos de constitución y desarrollo de las memorias colectivas que conviven en una misma comunidad histórica. En las sociedades actuales, todos los sujetos sociales luchan por preservar sus propias memorias, y al hacerlo, generan debates que no siempre se resuelven en la generación de nuevos consensos. Se trata, por lo tanto, de la coexistencia de múltiples memorias, que en algunas ocasiones rivalizan y compiten entre sí, dentro de los marcos consensuales de una cultura democrática. En este contexto, es posible propiciar lo que Achugar denomina el "olvido elegido" u "olvido consensual", que lejos de excluir la expresión de recuerdos dolorosos que afectan a algunos integrantes de la sociedad, pretende superarlos de una manera positiva, para "poder seguir adelante sin que el lamento constante impida la acción futura."

Recebido: 14/12/2009 - Aprovado: 24/02/2011

${ }^{78}$ CAETANO, Gerardo, Historia reciente, historia en construcción, op. cit., p. 197.

${ }^{79}$ ACHUGAR, Hugo. La nación entre el olvido y la memoria. Hacia una narración democrática de la nación. In: RICO, Álvaro (dir.). Uruguay, cuentas pendientes, op. cit., p. 24. 